\title{
Letter to the Editor: Response
}

\author{
JOSEPH B. WARSHAW
}

The University of Texas Health Science Center at Dallas, Southwestern Medical School, Dallas, Texas, USA

Dr. Butterfield states in his thoughtful letter that while my SPR presidential address brought the issue of academic departmental economics out of the closet it left us in the dark about solutions. It also implies that my talk reflected an elitist attitude which diminishes the importance of clinical contributions by skilled practitioners and perpetuated the town-gown "moat mentality." This view could not be further from the intent or spirit of my presentation. I fully recognize the contributions made by clinical scholars in the practicing community and in no way intended to diminish the importance of scholarly contributions and quality patient care by clinicians working in either the private sector or in academic departments. I was pleased to read that the faculty of

Copyright $\odot 1983$ International Pediatric Research Foundation, Inc. 0031-3998/83/1703-0238\$02.00/0 the Denver Children's Hospital's staff who hold full time academic appointments cheerfully generate their own support while maintaining active clinical research and collaborative interactions with university physicians. This is as it should be and is the model that I would expect in such a setting and would hope that those who can make such contributions do not have them diminished by purely financial needs to generate revenues. I regret that I left Dr. Butterfield in the dark and can only hope that the collegial interactions of private and university faculty that he envisions would at least "lighten" the burdens of faculty whose abilities to maintain research activities are threatened constantly because of the burdens to raise clinical monies. 